\title{
Impact of Online Learning of Economics in Lebanon on Acquiring Essential Skills in Light of the COVID-19 Pandemic
}

\author{
Hasan El-Mousawi ${ }^{1}$, Mohamad Zaraket $^{2}$ and Claude Bou-Assi ${ }^{3}$ \\ ${ }^{1}$ Lebanese University, Beirut, Lebanon \\ ${ }^{2}$ University of Sciences and Arts in Lebanon \\ ${ }^{3}$ Ministry of Education and Higher Education, Lebanon \\ * Prof. Hasan El-Mousawi, E-mail: hasan.almousawi@ul.edu.lb
}

\begin{abstract}
The sudden and recent outbreak of the Covid-19 had its impact on the way of life around the entire world; it challenged the education systems around the globe and forced schools and universities to switch to online education overnight. Several schools and universities that were formerly hesitant to change their traditional pedagogical approach had no choice but to entirely switch to online education. This study examines the impact of online learning of Economics on acquiring essential skills in light of the Coronavirus outbreak. The researchers used a descriptive-analytical approach and constructed a five-point Likert style questionnaire as a study tool. The questionnaire was distributed to a sample chosen from the population of Economics teachers in Lebanese schools. The sample consisted of 153 teachers all of which responded and their responses were valid for testing and analysis. The study reached some important findings mainly that through online learning of Economics, learners are not acquiring all of the 21st-Century skills, and the researchers had some recommendations as a result.
\end{abstract}

Keywords: E-learning, 21st-Century Skills, Covid-19

\section{How to Cite:}

El-Mousawi1, H., Zaraket, $M$ and Bou-Assi, C. (2022). Impact of online learning of economics in lebanon on acquiring essential skills in light of the Covid-19 pandemic. International Journal of Business, Management, and Economics, 3(1). 95 - 119. DOI: https://doi.org/10.47747/ijbme.v3i1.608

\section{Introduction}

Throughout history, the globe has always witnessed pandemics, plagues, and influenza epidemics, all of which have negatively impacted a great part of the world on both the economic and social levels. Currently, the world is under the impact of an outbreak of a respiratory illness which is a result of a novel Coronavirus (COVID-19). According to World Health Organization (WHO, Jan. 2021), this outbreak has initiated in the Chinese city of Wuhan and has expanded rapidly in 2020, causing a fast deterioration in the global economy (Organization for Economic Cooperation and Development, OECD, 2020a). COVID-19 has made an instantaneous negative impact on various industrial and non-industrial businesses; 
however, some sectors like entertainment, transportation, retail sales, schooling, and tourism were more affected than others.

The practice of remote activities, such as education and work, has become one of the main methods that countries have resorted to in order to face the repercussions of the spread of Coronavirus. The great technological progress in the field of communication has made it possible to manage a complete educational cycle without the need for instructors and learners to be in a narrow span of space (Department of Education and Training, Melbourne, 2020), and at the same time allow taking precautionary measures against the spread of Coronavirus.

There is no doubt that the education sector is one of the most affected by the health crisis that has imposed the search for means and solutions to fill the educational void, compensate for the educational deficiency, and bridge the knowledge gap that learners suffer from at various educational levels (OECD, 2020b). Technological progress has had a great impact on the entire educational process since education, with its traditional methods of transferring knowledge, was no longer able to fulfill the requirements of that process and attract large numbers of individuals in all its stages. Therefore, societies began to search for new formats of education that depend on the learner himself (self-learning), lifelong learning (UNESCO, 2020), as well as what we are at today, online education.

Online education is one of the most important concepts and modern technologies for education at all levels. It is worth noting that e-learning does not mean teaching the curricula and storing them on CDs, but the essence of online education is the interactive pattern, which means the existence of an interaction between learners and their instructors and among learners themselves (Bossér \& Lindahl, 2019). There is always an instructor who communicates with learners, explains for them, answers their questions gives them assignments, and conducts tests. Accordingly, online education is every modern educational method that is built on a technical basis using modern technological and educational aids and strategies to ensure interaction between the instructor and the learner to ensure that the latter acquires knowledge (Arley-Fonseca \& Brizuela-Gutiérrez, 2020).

In light of the current and exceptional circumstances that Lebanon is going through, ever since the outbreak of the October 17, 2019 protests until the outbreak of the Coronavirus pandemic, online education methods have been adopted at all educational levels (Mouchantaf, 2020). The main goal was to preserve the health and safety of citizens, to invest time, and not to miss any opportunity to educate learners. However, all that was without a unified vision and clear conditions for this type of education method. In spite of the positive returns that online education achieves, it faces several challenges (Abourjeili \& Harb, 2020), especially in developing countries that do not have the adequate technological infrastructure necessary to perform online education or those that suffer from economic issues.

Implementing the online education mechanism in Lebanon faces several obstacles. The main issue is that the culture of a great number of teachers' at all educational levels is still traditional (Lebanon Education Sector, 2021). Also, the majority of educational institutions in Lebanon do not have sufficient technological infrastructure to ensure the quality and productivity of education (Abourjeili \& Harb, 2020). In addition, the communication network infrastructure in Lebanon does not cover all regions of the country and the quality of the Internet is poor compared to what is available in most neighboring countries at least, noting that the subscription fee for this service is considered among the highest in the world (International Telecommunication Union, 2015). In addition, there is a great number of families who cannot afford an electronic device for each learner in the family due to the 
current economic and financial situation that Lebanon is facing (Save the Children International, 2021).

Before the outbreak of the novel Coronavirus, e-learning in Lebanon was not implemented at any of the schools, only a few higher education institutes used online platforms (Save the Children International, 2021). After the Covid-19 outbreak in Lebanon, the ministry of education in collaboration with the Educational Center for Research and Development (CRDP) started teaching sessions for students via the national Television. Nevertheless, it didn't get the aspired results, which lead to adopting online education using various platforms such as Microsoft Teams, Zoom, Google Classroom, Moodle, Blackboard, in addition to others. This unplanned leap into online education had many hindrances and resulted in a lot of problems for school administrations, teachers, students, and parents especially that, nowadays, education.

Based on the above, the researcher conducted the study at hand to assess the impact of online learning of Economics on acquiring essential skills that comply with the $21^{\text {st }}$-Century skills in light of the COVID-19 pandemic.

\section{Literature Review}

E-learning is something that has long been an issue of debate and controversy over the need to integrate it into the educational process even long before the Coronavirus pandemic; however, it became an alternative and an urgent necessity to continue education in conditions that impose physical distancing (Islam et al., 2015). Koumi (2006) believes that e-learning came as a result of technological developments, especially after the educational process was directly affected by the automation of industry and the development of "artificial intelligence" technology and "the Internet of things", as well as the information technology revolution that entered the classroom and became an integral part of it.

Due to the spread of the Coronavirus, educational institutions have suddenly found themselves forced to switch to online learning to ensure the continuity of the teaching and learning process, in addition to using the Internet, smartphones, and computers to communicate remotely with students (Yulia, 2020). The increase in the number of teachers and students who use computers, the Internet, and smartphones in the learning process is due to the characteristics of e-learning and its positive effects. The study of both Edwards and Fritz (1997) revealed that e-learning is enjoyable and interesting, effectively achieves the desired educational results, and improves students' acquisition of concepts. Ravaglia et al. (1995) conducted a study on the effect of using computers in teaching both mathematics and science in a program for gifted education at Stanford University in the United States of America. The study concluded that using computers in education increases effectiveness in learning.

Ferriman (2014) found that there exist many benefits and features for e-learning which traditional teaching methods don't have. One of these benefits is the reduction of costs as it saves the costs of creating new classrooms to conduct educational courses and seminars, and saves electricity, water, and other materials used in the school, in addition to the reduction of transportation costs. Another feature is that all learners of all age groups can benefit from the meetings and courses offered on the Internet, and gain new skills and experiences away from the restrictions of traditional schools. It also enhances the investment of time and increases 
learning since useless interactions between students decrease by reducing chatting and excessive questions that waste time, so the amount of what the student learns increases without the many disruptions or obstacles of the traditional teaching methods. Ferriman also depicted that e-learning is environmentally friendly, as there is no use of materials that may harm the environment when disposing of them.

However, Hetsevich (2017) believes that despite the many benefits of e-learning, it has some drawbacks. The study depicted its high reliance on technology; although e-learning is available to all individuals, many of them may not have smartphones, computers, or even a network. Also, because e-learning is self-directed, some people may find it difficult to motivate themselves to learn and resist playing and organizing the learning process. The study concluded that isolation and loneliness among e-learners rise because of the students' interaction with computers and smartphones instead of directly communicating and interacting with each other and with their teachers.

The effects of e-learning platforms on students' performance were studied on a large scale, where the amount and diversity of resources available to students increase their performance, especially when this diversity is compatible with the diversity of educational evaluation strategies (Gvaramadze, 2012; Jethro, et al., 2012). Another research (Halverson et al., 2012) aimed at exploring whether students' use of online resources affects their performance. The results showed that the amount and variety of resources students used enhanced their learning. However, the results indicate that the method of assessing prior learning outcomes and students' already acquired skills reduced this effect.

The School Education Gateway (an official website of the European Union) conducted a survey on online and distance learning (June 6, 2020) that attracted 4859 respondents from various countries across Europe, of which $86 \%$ were teachers or school heads. The results of the survey showed that, for about $70 \%$ of the respondents, it was their first-time experience with online education. The results also showed that the experience in online education gave $38.5 \%$ of them the freedom to experiment with teaching practice, and for $33.5 \%$ of them, it was a flexible experience. It also showed that $65 \%$ think online education comprises a wide range of tools, platforms, materials, and resources. However, according to $49 \%$ of the students and $34 \%$ of the teachers who responded, access to technology such as computers, software, stable Internet connection, etc., was a challenge, and 43\% reported high workload and stress due to working online from home.

In a study about the effect of Coronavirus on education in China, Xiao and Li (2020) claimed that teachers cannot effectively supervise and lead the online class. Also, student assessment is not as effective as in-person education; it was classified as imprecise. Surma \& Kirschner (2020) report that this problem is restricted by the lack of training for all parties of the teaching and learning process.

According to a report issued by the Lebanon Education Sector (2021), Lebanon is under the effect of interconnected social and economic problems that are impacting every aspect of life, risking students' education and futures because of the forced closure for long periods since October 2019, affecting a lot of students and keeping so many out of school. In a connected report, the UNICEF (June 2021) pointed out the inadequate access to e-learning tools (computer, tablet, smartphone, etc.), and highlighted the fact that students in Lebanon have had no meaningful learning for two academic years because of insufficient experience in elearning or the proper infrastructure to support it. It is worth mentioning that there exists a long-term problem with the electricity supply due to the economic and monetary crisis that Lebanon is facing (some regions don't get electricity for numerous consecutive days) in 
addition to the very high cost of getting electricity from private generators. Also, there is another related issue that is equally significant for e-learning, the Internet. It is considered among the highest in price among neighboring countries, and recently, it has been extremely unreliable.

The literature as demonstrated above discusses two positions related to e-learning: one views it as advantageous while the other views it as disadvantageous. However, none of the studies cited in the previous literature tackled the impact of e-learning on the skills that learners should acquire through the educational process. In the study at hand, the researchers assess the impact of online learning of Economics on acquiring essential skills that comply with the $21^{\text {st }}$-Century skills in light of the COVID-19 pandemic. This study is the first to be conducted about the topic in Lebanon as far as the researchers know.

\subsection{Conceptual Framework}

The education sector constitutes the cornerstone for the advancement of societies, which required investment in knowledge and scientific research, especially with the emergence of globalization and the growth of new industries. Thus, investment in the education process - in both the academic and professional domains - is a human investment. That is, "making an educated person" with the characteristics of the era that require moving away from the existing inactivity and indoctrination and moving to the vitality of learning based on discovery, investigation, analysis, and conclusion to deal with problems and their solution. Any form of education is, and should always be, centered on the learners, and this demands the diversification of knowledge sources and their forms, and employing the latest technology in this field. Among the many forms of education is a newly used type that was enforced all over the globe after the coronavirus outbreak, e-learning.

\subsection{E-learning}

There has been a wide-ranging discussion about a common definition of the term e-learning. The letter ' $\mathrm{e}$ ' in e-learning refers to the word "electronic"; thus, it includes all educational activities carried out by individuals or groups working online or offline, synchronously or asynchronously via computers, smartphones, or other electronic devices. The Internet has become a fundamental way of making resources for research and learning accessible for both instructors and learners to share and obtain information. E-learning Technology-based includes the use of the Internet and other essential technologies to generate teaching materials, educate learners, as well as to organize courses in the institute (Fry, 2001).

E-learning as a concept covers a set of applications, methods, and processes of learning. Thus, it is not easy to find a generally acknowledged definition of the term e-learning (Rossi, 2009). Oblinger and Hawkins (2005) and Dublin (2003) claim that there is not even one definition of the term. Nonetheless, Holmes and Gardner (2006) commented on these discrepancies by stating that there may be as many definitions of the term e-learning as there exist academic papers on the topic.

According to Chitra and Raj (2018), e-learning is the planned use of information and networkcommunication technology in teaching and learning. Online learning, virtual learning, distributed learning, networked, and web-based learning are also used to describe this style of teaching and learning. According to the Organization for Economic Cooperation and 
Development (OECD, 2005), e-learning is defined as the use of information and communication technology in diverse educational processes to support and enhance learning in higher education institutions it includes the use of information and communication technology as a supplement to the traditional classroom, online learning or a combination of the two modes.

Based on the above, the researcher concludes that e-learning is a concept that refers to the use of modern electronic means in the field of education, through which it is possible to store, collect and communicate information related to the various academic subjects in order to achieve the required efficiency of the education system.

\subsection{Advantages and Disadvantages of E-learning}

According to Firmansyah et al. (2021), Axmedova \& Kenjayeva (2021), Yuhanna et al. (2020) and Alshamrani (2019) e-learning has some advantages as well as disadvantages, as follows:

\section{- The advantages of e-learning include:}

1. Ease and speed of communication between the teacher and the student even outside the official working hours, as there are many immediate means of remote communication.

2. The different teaching methods and their suitability for students; there are students who suffer from difficulty in concentration, distraction, and the inability to organize ideas. E-learning allows the teacher to focus on important ideas and take into account order and arrangement in the explanation process so that the lecture is coordinated in an easy and comprehensible manner.

3. The availability of educational material throughout the day and all days of the week help many students to arrange their study time and enable them to carry out other work besides studying, so whoever wants to work or enroll in courses or a gym can organize his/her time in a way that does not interfere with studying.

4. The e-learning system is not dependent on the actual attendance of the student, as the student can study in any place that he/she prefers and is not restricted to studying at the university among students or in the library.

- The disadvantages of e-learning include:

1. The need for infrastructure, in terms of availability of computers, high-speed Internet connection, and the cost of its application is very high.

2. E-learning weakens students' motivation to learn, due to spending a lot of time in front of the computer screen and websites.

3. It is difficult to evaluate and develop standards of e-learning since it reduces the level of creativity and innovation when answering the exams, where the learner has to reply using the same answer fed into the program, and there is no room for discussing the answer or understanding it differently.

4. The need for specialists to manage e-learning systems, as it is not a simple system and needs experience and intelligence in implementation and application, so there is a need for a qualified staff capable of managing this technical system.

5. The presence of a large number of current teachers who are unable to use digital technology in a way that enables them to deal with it and teach through it. 
The Organization for Economic Cooperation and Development (OECD) has contributed to the wider range of education goals through the Definition and Selection of Competencies in the 1990s and the associated Program for International Student Assessment that was initiated in 1997, (also known as the $21^{\text {st }}$-Century skills) and more recently with the OECD 2030 Learning Framework that identifies an expanded set of competencies that can contribute to the individual and group well-being (OECD, 2020c). This framework consists of a learning compass that includes "Essential Knowledge, Skills, Attitudes and Values for the year 2030 that will not only cover literacy and numeracy, but also data, digital literacy, physical and mental health, and social and emotional skills."

At the beginning of the twenty-first century, organizations and economic entities posed an important question: "What competencies should citizens acquire to meet the needs of the new century?" Several frameworks for twenty-first-century competencies have published to answer this question. Many of these competencies have been adopted as educational or correctional objectives to nurture talent and skills. Organizations or economic entities have used different terms to describe the goals they pursue. These competencies are classified into three groups: learning, literacy, and life skills.

\subsection{Skills for the $21^{\text {st }}$-Century}

Training for thinking skills and the tools that enable people to understand the world around them has become a primary goal of education in the twenty-first century. The interest in teaching these skills has reached such a remarkable level that it is quite noticeable in the educational literature, conferences, plans for developing educational materials, and teacher training and preparation programs.

The $21^{\text {st }}$-Century Skills are 12 abilities, as shown below, that students today need to succeed in their careers as the world is currently fast-changing.

The twelve $21^{\text {st }}$-Century skills are:

1. Critical thinking: As cited in the "Foundation for Critical Thinking", the National Council for Excellence in Critical Thinking (1987), it is an intellectually disciplined process of conceptualizing, applying, analyzing, synthesizing, and/or evaluating information gathered from or resulting from observation, experience, reasoning, inference, or communication, as evidence for belief and action.

2. Creativity: Richard Howe defines creative thinking as being a way of turning someone into a problem solver and giving that individual a "toolbox" for dealing with problems. Creativity is a person's ability to create something that appropriately qualified people would consider original and valuable (Wyse, 2018).

3. Collaboration: Lai (2011) define it as shared involvement of participants in a harmonized effort to find a solution for a problem.

4. Communication: It is a requirement for any organization to maintain profitability. It is crucial for students to learn how to effectively transfer ideas between the different types of personality. This has the potential to eliminate confusion in the workplace, making students valuable parts of their teams, departments, and companies (Griffin \& Care, 2015). 
5. Information literacy: The Association of Colleges and Research Libraries (ACRL, 2015) defines information literacy as "a set of integrated capabilities that include the reflexive discovery of information, understanding how information is produced and evaluated, using the information to create new knowledge and ethically participating in learning societies."

6. Media literacy: Yanarates (2020) defines media literacy as the set of perspectives through which we expose ourselves to the media and explain the meaning of the messages we come across.

7. Technology literacy: Technology literacy corresponds to digital literacy in that when an individual is proficient in using computers and/or other digital devices to access the Internet. Technology literacy allows one to use the Internet to discover, review, evaluate, create, and use information across various digital platforms (Siegle, 2004).

8. Flexibility: Cognitive flexibility is a higher-order thinking skill and an aspect of executive functions. It is about immediate consideration of multiple points of view and the ability to make changes in one's thoughts or beliefs (Barak \& Levenberg, 2016).

9. Leadership: Leadership is a multidimensional and integrated vision of leadership based on relationships. Through joint goals and expectations, leadership offers new ways of being, knowing, and acting, while respecting the developmental nature of human life (Rost, 1991).

10. Initiative: People should learn initiative, that is self-starting, in order to fully succeed since it comes naturally to very few people. Initiative, which is one of the most difficult skills to learn, means that the learner must work on projects outside the working hours (Bialik \& Fadel, 2015).

11. Productivity: Productivity is the ability to create a product using these skills: setting and achieving goals, prioritizing needs, managing time, working ethically, and collaborating with colleagues and customers. It is called efficiency as relative to business, which means getting more done in less time (Kivunja, 2014)

12. Social skills: The Indeed Editorial Team (2020) considers that social skills are used to communicate with others on a daily basis in a variety of ways including verbal and nonverbal, written and visual. Social skills are also referred to as interpersonal relationships. Social skills are essential for building personal and professional relationships.

These skills are intended to help learners keep up with today's modern markets. Each skill is unique in how it helps learners, but they can jointly help the new generation grow as they are basic in the age of the Internet. The researchers are studying the impact of online learning of Economics on acquiring essential skills that comply with the $21^{\text {st }}$-Century skills in light of the COVID-19 pandemic, which are classified into 3 groups: learning, literacy, and life skills.

\subsection{Research Problem and Hypotheses}

Recently, the trend of education is toward achieving essential skills that comply with $21^{\text {st }}$ Century skills. In the past two years, the globe has been experiencing the outbreak of a serious pandemic (COVID-19), which forced schools to close and turn to online education. The main issue that this study tackles is whether or not online learners of economics are acquiring $21^{\text {st }}$ Century skills. This being the case, the researchers have the following questions in mind:

The first main question: Do economics teachers acquire the essential skills through online education? 
The second main question: Are online learners of economics acquiring $21^{\text {st }}$-Century skills?

From the above question, the following sub-questions arise:

- Are online learners of economics acquiring learning skills?

- Are online learners of economics acquiring literacy skills?

- Are online learners of economics acquiring life skills?

The third main question: Are there any hindrances to applying online learning at schools?

Based on the above questions, the researchers have the following hypotheses:

$\mathrm{H}_{1}$ : Economics teachers acquire the essential skills through online education.

$\mathrm{H}_{2}$ : Online learners of economics are not acquiring $21^{\text {st }}$-Century skills.

From the hypothesis $\mathrm{H}_{2}$, the following 3 sub-hypotheses arise:

$\mathrm{H}_{2.1}$ : Online learners of economics are not acquiring learning skills.

$\mathrm{H}_{2.2}$ : Online learners of economics are not acquiring literacy skills.

$\mathrm{H}_{2.3}$ : Online learners of economics are not acquiring life skills.

$\mathrm{H}_{3}$ : There are hindrances to applying online learning at schools.

\section{Research Methods}

The researchers adopted the descriptive-analytical approach, utilizing an empirical study. The researchers constructed a five-point Likert style questionnaire of 29 items to be distributed to a population of teachers working at private and public schools in Lebanon. A large sample of teachers was selected using convenient methods. The researchers use multivariate data analysis to come up with results based on which, some recommendations can be set forth to develop online in the educational process in light of the Coronavirus outbreak.

\subsection{Population and Sample Selection}

The population of the research consists of all economics teachers of secondary schools in Lebanon. The researchers chose a sample of 153 economics teachers from the population and distributed the questionnaire among them, all of which responded and were valid for testing and analysis. The demographic data of the sample is shown below:

Table 1. The Sample's Distribution according to Demographic Data

\begin{tabular}{cccc}
\hline Variable & Category & Frequency & Percentage \\
\hline \multirow{3}{*}{ Education } & Bachelor & 54 & 35.3 \\
& Masters & 89 & 58.2 \\
Total & Ph.D. & 10 & 6.5 \\
& & $\mathbf{1 5 3}$ & $\mathbf{1 0 0 . 0}$ \\
Years of experience & $0-5$ years & 9 & 5.9 \\
& $5-10$ years & 20 & 13.1 \\
Total & More than 10 years & 124 & 81.0 \\
& & $\mathbf{1 5 3}$ & $\mathbf{1 0 0 . 0}$ \\
\hline
\end{tabular}


It is evident from Table (1) that $35.3 \%$ of the sample have bachelor's degrees, $58.2 \%$ have master's degrees and $6.5 \%$ have Ph.Ds. It is also evident that the majority of the sample $(81 \%)$ have more than 10 years of experience in teaching economics, which means that the majority of the sample have professional and reliable responses for the items of the questionnaire about the subject matter of the study at hand.

\subsection{Instrumentation}

Based on the previous studies, in addition to the researchers' personal experience, the researchers constructed a five-point Likert Style questionnaire with 29 items. The scale of the five-point Likert style is as follows in Table (2):

Table 2. The Scale of the five-point Likert style

\begin{tabular}{llllll}
\hline Answer & Strongly agree & Agree & Neutral & Disagree & Strongly disagree \\
\hline Degree & 5 & 4 & 3 & 2 & 1 \\
\hline
\end{tabular}

\subsection{Validity and Reliability}

Findings of the current study show that Cronbach's Alpha for all the items of the questionnaire is as shown in the table below:

Table 3. Cronbach's Alpha Coefficient

\begin{tabular}{cc}
\hline \multicolumn{2}{c}{ Reliability Statistics } \\
\hline Cronbach's Alpha & N of Items \\
0.757 & 29 \\
\hline
\end{tabular}

Table (3) shows that Cronbach's alpha is $0.757>0.7$, which indicates that items of the questionnaire are reliable.

4. Result and Discussion

\subsection{Data Analysis}

Since the quintet Likert Scale was used in designing the tool of the study, the research adopts the standard illustrated in Table (4) which follows to judge the inclination of each item when using the quintet Likert Scale depending mainly on the mean value and relative weight to determine the extent of consent to the items and domains of the questionnaire.

Table 4. Scale Used in the Study according to the Mean and Relative Weight

\begin{tabular}{lccccc}
\hline & \multicolumn{5}{c}{ Approval Level } \\
\cline { 2 - 6 } Mean & Very low & Low & Medium & High & Very high \\
Relative Weight & $<1.8$ & $1.8-2.59$ & $2.6-3.39$ & $3.4-4.19$ & $>4.2$ \\
\hline
\end{tabular}

\subsection{Testing and Discussing the Hypothesis}

To test the hypothesis, the researchers calculated the mean, standard deviation, relative weight, and importance level of each item of the questionnaire relative to the study. Also, the 
One-Sample t-Test was used to determine the relevance of the responses to the value (3) which reflects neutrality. The results are shown below:

Hypothesis 1: Economics teachers acquire the essential skills through online education.

\section{Table 5. Statistical analysis of the first domain (Online Learning)}

\begin{tabular}{lcccccc}
\hline \multicolumn{1}{c}{ Items } & Mean & S.D & $\begin{array}{c}\text { Rel. } \\
\text { Wt. }\end{array}$ & T-Test & $\begin{array}{c}\text { P- } \\
\text { value }\end{array}$ & $\begin{array}{c}\text { Imp. } \\
\text { Level }\end{array}$ \\
\hline $\begin{array}{l}\text { 1. Online sessions can be managed and } \\
\text { organized easily. }\end{array}$ & 2.69 & 1.084 & $53.8 \%$ & -3.506 & 0.001 & Medium \\
$\begin{array}{l}\text { 2. Delivering online sessions can save time. } \\
\text { 3. Online education allows teachers enough }\end{array}$ & 2.73 & 1.070 & $54.6 \%$ & -3.098 & 0.002 & Medium \\
$\begin{array}{l}\text { time to answer and discuss learners' } \\
\text { questions. }\end{array}$ & 2.73 & 1.154 & $54.6 \%$ & -2.942 & 0.004 & Medium \\
$\begin{array}{l}\text { 4. Online education helps teachers acquire } \\
\text { new teaching strategies. }\end{array}$ & 4.08 & 0.654 & $81.6 \%$ & 20.390 & 0.000 & High \\
$\begin{array}{l}\text { 5. Online education helps teachers use new } \\
\text { teaching aids. }\end{array}$ & 4.12 & 0.499 & $82.4 \%$ & 27.692 & 0.000 & High \\
$\begin{array}{l}\text { 6. Online education helps teachers use } \\
\text { active learning techniques. }\end{array}$ & 3.99 & 0.716 & $79.8 \%$ & 17.044 & 0.000 & High \\
$\begin{array}{l}\text { 7. Online education allows teachers to } \\
\text { deliver sessions in attractive and interesting } \\
\text { ways. }\end{array}$ & 3.90 & 0.696 & $78 \%$ & 16.041 & 0.000 & High \\
$\quad$ Total & 3.462 & 0.528 & $69.2 \%$ & 10.814 & 0.000 & \\
\hline
\end{tabular}

The above table shows the following:

1. The item which states "Online sessions can be managed and organized easily" has a relative weight of $53.8 \%$, and the mean is 2.69 , which is less than the neutral value of 3 . Also, the value of the calculated " $T$ " test is -3.506 , which is less than the value of tabulated " $T$ " at the significance 0.05 . Consequently, online sessions can't be managed and organized easily".

The researchers believe that the result was as such since economics teachers may not be well-trained in managing and organizing an online class as teaching online came suddenly as a result of the coronavirus pandemic. Moreover, some students don't have enough responsibility to take the online sessions seriously, so they don't control their behavior. In addition, the unreliable electricity and Internet in Lebanon play a role in disrupting the sessions' progress.

2. The item which states "Delivering online sessions can save time" has a relative weight of $54.6 \%$, and the mean is 2.73 , which is less than the neutral value of 3 . Also, the value of the calculated " $T$ " test is -3.098 , which is less than the value of tabulated " $T$ " at the significance 0.05. Consequently, delivering online sessions can't save time".

The researchers believe that the result was as such since economics teachers would prepare their lessons using PowerPoint presentations or PDFs, and search for visual aids (pictures and/or videos) which takes a lot of the teachers' time. In addition, they would type their lessons and exercises for practice. 
3. The item which states "online education allows teachers enough time to answer and discuss learners' questions" has a relative weight of $54.6 \%$, and the mean is 2.73 , which is less than the neutral value of 3 . Also, the value of the calculated " $T$ " test is -2.942 , which is less than the value of tabulated " $\mathrm{T}$ " at the significance 0.05 . Consequently, online education doesn't allow teachers enough time to answer and discuss learners' questions".

The researchers believe that the result was as such since online sessions are relatively short since most of the programs used in Lebanese schools for online education give only 40 minutes for the session, 5 of which would be for students to join the session. That would leave teachers with 35 minutes per session, and given the bad connection and electric supply, more valuable minutes would be spent on repeating for late students, let alone those who couldn't be online for one reason or another.

4. The item which states "online education helps teachers acquire new teaching strategies" has a relative weight of $81.6 \%$, and the mean is 4.08 , which is greater than the neutral value of 3. Also, the value of the calculated " $T$ " test is 20.390 , which is greater than the value of tabulated " $T$ " at the significance 0.05 . This means that there is an increase of statistical significance to the neutral level in the average responses of the members of the sample; consequently, online education helps teachers acquire new teaching strategies".

The researchers believe that the result came as such since teachers would like their students to benefit most from the online sessions, so they try their best to search for good strategies that would get their students to grasp the ideas in the session.

5. The item which states "online education helps teachers use new teaching aids" has a relative weight of $82.4 \%$, and the mean is 4.12 , which is greater than the neutral value of 3 . Also, the value of the calculated " $T$ " test is 27.692 , which is greater than the value of tabulated " $T$ " at the significance 0.05 . This means that there is an increase of statistical significance to the neutral level in the average responses of the members of the sample; consequently, "online education helps teachers acquire new teaching strategies".

The researchers believe that having to work on their computers, teachers have a lot of resources they might need to make their session a success. Thus, they can find online useful things (such as photos, videos, lesson plans, etc.) posted by other teachers from all over the world related to the materials they teach. Also, they are able to see what other teachers use to make learners understand the explanation and acquire the objectives of the sessions.

6. The item which states "online education helps teachers use active learning techniques" has a relative weight of $79.8 \%$, and the mean is 3.99 , which is greater than the neutral value of 3. Also, the value of the calculated " $T$ " test is 17.044, which is greater than the value of tabulated " $T$ " at the significance 0.05 . This means that there is an increase of statistical significance to the neutral level in the average responses of the members of the sample; consequently, "online education helps teachers use active learning techniques".

The researchers think that teachers have more time to spend over the computers since they are preparing an online session, so they would find convenient active learning techniques for their sessions, such as picture prompt, choral response, instructor storytelling, pass the pointer, empty outlines, etc.

7. The item which states "online education allows teachers deliver sessions in attractive and interesting ways" has a relative weight of $78 \%$, and the mean is 3.90 , which is greater than the neutral value of 3. Also, the value of the calculated " $T$ " test is 16.041, which is greater than the value of tabulated " $\mathrm{T}$ " at the significance 0.05 . This means that there is an increase 
of statistical significance to the neutral level in the average responses of the members of the sample; consequently, "online education allows teachers deliver sessions in attractive and interesting ways".

The researchers believe that teachers are using resources from the Internet (such as photos, videos, PowerPoint presentations, etc.) so that their sessions would attract the learners' attention.

It is clear from the above table that the overall mean of the sample responses for the first domain (Teachers' acquisition of skills) is 3.462 which is greater than the neutral value (3), indicating the sample agreement that economics teachers acquire the essential skills through online education. The standard deviation is 0.528 and the relative weight is $69.2 \%$. Also, the value of the calculated T-Test is 10.814 . The P-value for the hypothesis is equal to 0.000 which is less than the significance level 0.05 ; therefore, the first hypothesis which states "economics teachers acquire the essential skills through online education" is accepted.

Hypothesis 2: Online learners are not acquiring $21^{\text {st }}$-Century skills.

Hypothesis 2.1: Online learners are not acquiring the essential learning skills.

Table 6. Statistical analysis of the second domain (21st-Century Skills/Learning Skills)

\begin{tabular}{|c|c|c|c|c|c|c|}
\hline Items & Mean & S.D & $\begin{array}{l}\text { Rel. } \\
\text { Wt. }\end{array}$ & T-Test & $\begin{array}{c}\text { P- } \\
\text { value }\end{array}$ & $\begin{array}{l}\text { Imp. } \\
\text { Level }\end{array}$ \\
\hline $\begin{array}{l}\text { 1. Online education allows learners to } \\
\text { acquire the skill of problem-solving. }\end{array}$ & 3.83 & 0.864 & $76.6 \%$ & 11.878 & 0.000 & High \\
\hline $\begin{array}{l}\text { 2. Online education allows learners to } \\
\text { generate new ideas. }\end{array}$ & 2.09 & 0.955 & $41.8 \%$ & -11.763 & 0.000 & Low \\
\hline $\begin{array}{l}\text { 3. Online education allows learners to } \\
\text { acquire the skill of communicating with } \\
\text { others and listening to them. }\end{array}$ & 2.86 & 0.854 & $57.2 \%$ & -2.083 & 0.039 & Medium \\
\hline $\begin{array}{l}\text { 4. Online education allows learners to } \\
\text { acquire the skill of working with others. }\end{array}$ & 1.86 & 0.663 & $37.2 \%$ & -21.336 & 0.000 & Low \\
\hline Total & 2.658 & 0.518 & $53.2 \%$ & -8.149 & 0.000 & \\
\hline
\end{tabular}

1. The item which states "online education allows learners to acquire the skill of problemsolving" has a relative weight of $76.6 \%$, and the mean is 3.83 , which is greater than the neutral value of 3 . Also, the value of the calculated " $T$ " test is 11.878 , which is greater than the value of tabulated " $T$ " at the significance 0.05 . This means that there is an increase of statistical significance to the neutral level in the average responses of the members of the sample; consequently, "online education allows learners to acquire the skill of problemsolving".

The researchers think that students would want to search online for a solution for some problems they might face and hinder understanding their lessons.

2. The item which states "online education allows learners to generate new ideas" has a relative weight of $41.8 \%$, and the mean is 2.09 , which is less than the neutral value of 3 . 
Also, the value of the calculated "T" test is -11.763 , which is less than the value of tabulated " $T$ " at the significance 0.05 . Consequently, "online education does not allow learners to generate new ideas".

The researchers believe that some students would be dependent on others to answer the teachers' questions that require getting new ideas related to the lesson being discussed. Also, due to the unreliable Internet connection and electricity, teachers might not have enough time to enrich the sessions with activities and/or strategies that can enhance students to generate new ideas. Rather, teachers might have the new, desired ideas ready for their students beforehand.

3. The item which states "online education allows learners to acquire the skill of communicating with others and listening to them" has a relative weight of $57.2 \%$, and the mean is 2.86 , which is less than the neutral value of 3 . Also, the value of the calculated " $T$ " test is -2.083 , which is less than the value of tabulated " $T$ " at the significance 0.05 . Consequently, "online education does not allow learners to acquire the skill of communicating with others and listening to them".

The researchers believe that this might be because students talk simultaneously because of the bad Internet connection or might not know that others are talking. In addition, this is directly consequential to class management.

4. The item which states "online education allows learners to acquire the skill of working with others" has a relative weight of $37.2 \%$, and the mean is 1.86 , which is less than the neutral value of 3. Also, the value of the calculated "T" test is -21.336 , which is less than the value of tabulated " $T$ " at the significance 0.05 . Consequently, "online education does not allow learners to acquire the skill of working with others".

The researchers believe that during online sessions since students are separated (each one is at his/her home), this prevents them from working together during the session.

It is clear from the above table that the overall mean of the sample responses for the second domain $\left(21^{\text {st }}\right.$-Century Skills/Learning Skills) is 2.658 which is less than the neutral value (3), indicating the sample disagreement that online learners are acquiring the essential learning skills. The standard deviation is 0.518 and the relative weight is $53.2 \%$. Also, the value of the calculated T-Test is -8.149 .

The P-value for the hypothesis is equal to 0.000 which is less than the significance level 0.05 ; therefore, the sub-hypothesis that states "online learners are not acquiring the essential learning skills" is accepted.

Hypothesis 2.2: Online learners are not acquiring the essential literacy skills.

Table 7. Statistical analysis of the second domain (21st-Century Skills/Literacy Skills)

\begin{tabular}{|c|c|c|c|c|c|c|}
\hline Items & Mean & S.D & $\begin{array}{l}\text { Rel. } \\
\text { Wt. }\end{array}$ & T-Test & $\begin{array}{c}\text { P- } \\
\text { value }\end{array}$ & $\begin{array}{c}\text { Imp. } \\
\text { Level }\end{array}$ \\
\hline $\begin{array}{l}\text { 1. Online education encourages learners to } \\
\text { master types of information (facts, figures, } \\
\text { statistics, data). }\end{array}$ & 1.86 & 0.663 & $37.2 \%$ & -21.336 & 0.000 & Low \\
\hline $\begin{array}{l}\text { 2. Online education allows learners to } \\
\text { understand various forms of information } \\
\text { with an ability to make sense of what is } \\
\text { presented. }\end{array}$ & 2.09 & 0.955 & $41.8 \%$ & -11.763 & 0.000 & Low \\
\hline 3. Online education helps learners master & 4.08 & 0.591 & $81.6 \%$ & 22.578 & 0.000 & High \\
\hline
\end{tabular}


using various forms of communication

devices (computers, smartphones, tabs, etc.).

$\begin{array}{llllll}\text { Total } & 2.675 & 0.474 & 53.5 \% & -8.464 & 0.000\end{array}$

1. The item which states "online education encourages learners to master types of information (facts, figures, statistics, data)" has a relative weight of $37.2 \%$, and the mean is 1.86 , which is less than the neutral value of 3 . Also, the value of the calculated " $T$ " test is -21.336 , which is less than the value of tabulated "T" at the significance 0.05. Consequently, "online education does not encourage learners to master types of information (facts, figures, statistics, data)".

The researchers believe that students make mistakes frequently when it comes to numbers and statistics while they are in class at school, so it is inevitable for them to make mistakes about numbers and statistics when the session is online for the many reasons mentioned before. Also, learners would need to be guided through understanding figures and some facts step by step, which, according to the sample, is difficult.

2. The item which states "online education encourages learners to understand various forms of information with an ability to make sense of what is presented" has a relative weight of $41.8 \%$, and the mean is 2.09 , which is less than the neutral value of 3 . Also, the value of the calculated "T" test is -11.763 , which is less than the value of tabulated " $T$ " at the significance 0.05. Consequently, "online education does not encourage learners to understand various forms of information with an ability to make sense of what is presented".

Based on their experience, the researchers believe that a lot of students get confused when faced with new ideas and concepts, which they are unable to comprehend by themselves.

3. The item which states "online education helps learners master using various forms of communication devices (computers, smartphones, tabs, etc.)" has a relative weight of $81.6 \%$, and the mean is 4.08 , which is greater than the neutral value of 3 . Also, the value of the calculated " $T$ " test is 22.578 , which is greater than the value of tabulated " $T$ " at the significance 0.05 . This means that there is an increase of statistical significance to the neutral level in the average responses of the members of the sample; consequently, "online education helps learners master using various forms of communication devices (computers, smartphones, tabs, etc.)".

The researchers think that this is apparently true since students need one of these devices to work in online sessions so learners would acquire knowledge about the devices they are using.

It is clear from the above table that the overall mean of the sample responses for the second domain (21st-Century Skills/ Literacy Skills) is 2.675 which is less than the neutral value (3), indicating the sample disagreement that online learners are acquiring the essential literacy skills. The standard deviation is 0.474 and the relative weight is $53.5 \%$. Also, the value of the calculated T-Test is -8.464 . 
The P-value for the hypothesis is equal to 0.000 which is less than the significance level 0.05; therefore, the sub-hypothesis that states "online learners are not acquiring the essential literacy skills" is accepted.

Hypothesis 2.3: Online learners are not acquiring the essential life skills.

Table 8. Statistical analysis of the second domain (21st-Century Skills/Life Skills)

\begin{tabular}{|c|c|c|c|c|c|c|}
\hline Items & Mean & S.D & $\begin{array}{l}\text { Rel. } \\
\text { Wt. }\end{array}$ & T-Test & $\begin{array}{c}\mathbf{P}- \\
\text { value }\end{array}$ & $\begin{array}{l}\text { Imp. } \\
\text { Level }\end{array}$ \\
\hline $\begin{array}{l}\text { 1. Online education encourages learners to } \\
\text { adapt to situations and become flexible, open- } \\
\text { minded and self-confident. }\end{array}$ & 3.73 & 0.954 & $74.6 \%$ & 9.402 & 0.000 & High \\
\hline $\begin{array}{l}\text { 2. Online education helps learners become } \\
\text { more influential and use others' strengths to } \\
\text { achieve common goals. }\end{array}$ & 2.15 & 0.916 & $43 \%$ & -11.473 & 0.000 & Low \\
\hline $\begin{array}{l}\text { 3. Online education promotes enhancing } \\
\text { learners' potentials. }\end{array}$ & 3.57 & 1.117 & $71.4 \%$ & 6.299 & 0.000 & High \\
\hline $\begin{array}{l}\text { 4. Online education helps learners set their } \\
\text { own goals. }\end{array}$ & 1.96 & 0.595 & $39.2 \%$ & -21.613 & 0.000 & Low \\
\hline $\begin{array}{l}\text { 5. Online education allows learners to } \\
\text { monitor the extent of their } \\
\text { comprehensiveness and their education needs. }\end{array}$ & 2.73 & 1.118 & $54.6 \%$ & -2.965 & 0.004 & Medium \\
\hline $\begin{array}{l}\text { 6. Online education allows learners to } \\
\text { become self-accountable. }\end{array}$ & 2.35 & 1.091 & $47 \%$ & -7.336 & 0.000 & Low \\
\hline $\begin{array}{l}\text { 7. Online education allows learners to make } \\
\text { the best use of their time. }\end{array}$ & 3.33 & 0.896 & $66.6 \%$ & 4.602 & 0.000 & Medium \\
\hline $\begin{array}{l}\text { 8. Online education allows learners to } \\
\text { accomplish their tasks on time. }\end{array}$ & 2.05 & 0.764 & $41 \%$ & -15.453 & 0.000 & Low \\
\hline Total & 2.733 & 0.458 & $54.6 \%$ & -7.185 & 0.000 & \\
\hline
\end{tabular}

1. The item which states "online education encourages learners to adapt to situations and become flexible, open-minded and self-confident" has a relative weight of $74.6 \%$, and the mean is 3.73 , which is greater than the neutral value of 3 . Also, the value of the calculated " $T$ " test is 9.402, which is greater than the value of tabulated " $T$ " at the significance 0.05 . This means that there is an increase of statistical significance to the neutral level in the average responses of the members of the sample; consequently, "online education encourages learners to adapt to situations and become flexible, open-minded and selfconfident".

The researchers believe that having to learn online, students are working alone and find themselves compelled to be patient and listen to others and discuss with them to acquire the objectives of the lesson. Consequently, they become more flexible and open-minded.

2. The item which states "online education helps learners become more influential and use others' strengths to achieve common goals" has a relative weight of $43 \%$, and the mean is 2.15 , which is less than the neutral value of 3 . Also, the value of the calculated " $T$ " test is 11.473, which is less than the value of tabulated " $T$ " at the significance 0.05 . Consequently, "online education does not help learners become more influential and use others' strengths to achieve common goals".

3. The item which states "online education promotes enhancing learners' potentials" has a relative weight of $71.4 \%$, and the mean is 3.57 , which is greater than the neutral value of 3 . Also, the value of the calculated " $T$ " test is 6.299 , which is greater than the value of tabulated " $T$ " at the significance 0.05 . This means that there is an increase of statistical 
significance to the neutral level in the average responses of the members of the sample; consequently, "online education promotes enhancing learners' potentials".

The researchers think that students learning online have to rely on themselves since they are on their own most of the time and have to work harder to acquire the objectives of the lessons they are attending. Thus, their potentials appear to become more evident.

4. The item which states "online education helps learners set their own goals" has a relative weight of $39.2 \%$, and the mean is 1.96 , which is less than the neutral value of 3 . Also, the value of the calculated " $T$ " test is -21.613 , which is less than the value of tabulated "T" at the significance 0.05 . Consequently, "online education does not help learners set their own goals".

The researchers believe that only a few students, the good ones, would develop this skill as they are keen on their education. Others might not be so concerned about studying.

5. The item which states "online education allows learners to monitor the extent of their comprehensiveness and their education needs" has a relative weight of $54.6 \%$, and the mean is 2.73 , which is less than the neutral value of 3 . Also, the value of the calculated " $T$ " test is -2.965 , which is less than the value of tabulated " $T$ " at the significance 0.05 . Consequently, "online education does not allow learners to monitor the extent of their comprehensiveness and their education needs".

The researchers believe that the results may have come as such since the learners do not have the books related to the material they are studying online; they take whatever material the teachers supply. As such learners would not be able to determine their educational needs.

6. The item which states "online education allows learners to become self-accountable" has a relative weight of $47 \%$, and the mean is 2.35 , which is less than the neutral value of 3 . Also, the value of the calculated " $T$ " test is -7.336 , which is less than the value of tabulated "T" at the significance 0.05. Consequently, "online education does not allow learners to become self-accountable".

The researchers believe that this may be because students would not feel guilty about missing their online sessions because of the unreliable Internet connection or power failure as they would be able to see a recording of the session.

7. The item which states "online education allows learners to make the best use of their time" has a relative weight of $66.6 \%$, and the mean is 3.33 , which is greater than the neutral value of 3 . Also, the value of the calculated " $T$ " test is 4.602 , which is greater than the value of tabulated " $T$ " at the significance 0.05 . This means that there is an increase of statistical significance to the neutral level in the average responses of the members of the sample; consequently, "online education allows learners to make the best use of their time".

The researchers think that it is logical that online learners must organize their time to do the required tasks and have some time for themselves to refresh.

8. The item which states "online education allows learners to accomplish their tasks on time" has a relative weight of $41 \%$, and the mean is 2.05 , which is less than the neutral value 3 . 
Also, the value of the calculated "T" test is -15.453 , which is less than the value of tabulated " $T$ " at the significance 0.05 . Consequently, "online education does not allow learners to accomplish their tasks on time".

The researchers believe that some students might have complaints about the load they have from online learning which would leave them behind on certain tasks. Also, some students may get too immersed in their free time that they would not have enough time to finish their required tasks in due time.

It is clear from the above table that the overall mean of the sample responses for the second domain (21st-Century Skills/ Life Skills) is 2.733 which is less than the neutral value (3), indicating the sample disagreement that online learners are acquiring the essential life skills. The standard deviation is 0.458 and the relative weight is $54.6 \%$. Also, the value of the calculated T-Test is -7.185 .

The P-value for the hypothesis is equal to 0.000 which is less than the significance level 0.05; therefore, the sub-hypothesis which states "online learners are not acquiring the essential life skills" is accepted.

Hypothesis 3: There are hindrances to applying online learning at schools.

Table 9. Statistical analysis of the third domain (Challenges that may hinder online learning)

\begin{tabular}{|c|c|c|c|c|c|c|}
\hline Items & Mean & S.D & $\begin{array}{l}\text { Rel. } \\
\text { Wt. }\end{array}$ & T-Test & $P$-value & $\begin{array}{l}\text { Imp. } \\
\text { Level }\end{array}$ \\
\hline $\begin{array}{l}\text { 1. The speed of the internet connection is } \\
\text { inadequate and the session is constantly } \\
\text { disrupted. }\end{array}$ & 4.21 & 0.783 & $84.2 \%$ & 19.089 & 0.000 & $\begin{array}{l}\text { Very } \\
\text { High }\end{array}$ \\
\hline 2. The electricity is not reliable. & 4.29 & 0.742 & $85.8 \%$ & 21.563 & 0.000 & $\begin{array}{l}\text { Very } \\
\text { High }\end{array}$ \\
\hline $\begin{array}{l}\text { 3.Accessing the educational material is not } \\
\text { easy. }\end{array}$ & 3.95 & 0.872 & $79 \%$ & 13.443 & 0.000 & High \\
\hline $\begin{array}{l}\text { 4. Sending and receiving educational } \\
\text { material is not easy. }\end{array}$ & 3.58 & 1.104 & $71.6 \%$ & 6.442 & 0.000 & High \\
\hline $\begin{array}{l}\text { 5. Some learners do not have access to } \\
\text { proper communication devices (computer, } \\
\text { tab, smartphone). }\end{array}$ & 3.76 & 1.076 & $75.2 \%$ & 8.714 & 0.000 & High \\
\hline $\begin{array}{l}\text { 6. There are always some absent learners } \\
\text { during online sessions. }\end{array}$ & 4.29 & 0.511 & $85.8 \%$ & 31.296 & 0.000 & $\begin{array}{l}\text { Very } \\
\text { High }\end{array}$ \\
\hline $\begin{array}{l}\text { 7. The available online learning evaluation } \\
\text { methods (multiple choice, true or false, short } \\
\text { answers, etc.) do not accurately measure } \\
\text { learners acquisition of skills and } \\
\text { competences. }\end{array}$ & 4.36 & 0.624 & $87.2 \%$ & 26.938 & 0.000 & $\begin{array}{l}\text { Very } \\
\text { High }\end{array}$ \\
\hline Total & 4.062 & 0.545 & $81.2 \%$ & 24.075 & 0.000 & \\
\hline
\end{tabular}

1. The item which states "the speed of the internet connection is inadequate and the session is constantly disrupted" has a relative weight of $84.2 \%$, and the mean is 4.21 , which is greater than the neutral value of 3 . Also, the value of the calculated "T" test is 19.089 , which is greater than the value of tabulated " $T$ " at the significance 0.05 . This means that there is an increase of statistical significance to the neutral level in the average responses of the members of the sample; consequently, "the speed of the internet connection is inadequate and the session is constantly disrupted".

The researchers think that it is well-known that the Internet connection in Lebanon is slow; moreover, it became yet slower due to the current financial and economic crisis 
Lebanon is facing since the ministry of communication is having difficulty in getting the necessary equipment to maintain this sector.

2. The item which states "the electricity is not reliable" has a relative weight of $85.8 \%$, and the mean is 4.29 , which is greater than the neutral value of 3 . Also, the value of the calculated " $T$ " test is 21.563 , which is greater than the value of tabulated " $T$ " at the significance 0.05 . This means that there is an increase of statistical significance to the neutral level in the average responses of the members of the sample; consequently, "the electricity is not reliable".

Before the current financial and economic crisis in Lebanon, there was a constant shortage of power (an average of 12 hours a day). Nowadays, it came down to only about 3-4 hours a day, and one can never know when it would be on or when it would go off.

3. The item which states "accessing the educational material is not easy" has a relative weight of $79 \%$, and the mean is 3.95 , which is greater than the neutral value of 3 . Also, the value of the calculated " $T$ " test is 13.443 , which is greater than the value of tabulated " $T$ " at the significance 0.05 . This means that there is an increase of statistical significance to the neutral level in the average responses of the members of the sample; consequently, "accessing the educational material is not easy".

Based on their experience, the researchers believe that the Lebanese curriculum is very old (it was last updated twenty-one years ago) and isn't compatible with online education.

4. The item which states "sending and receiving educational material is not easy" has a relative weight of $71.6 \%$, and the mean is 3.58 , which is greater than the neutral value of 3 . Also, the value of the calculated " $T$ " test is 6.442 , which is greater than the value of tabulated " $T$ " at the significance 0.05 . This means that there is an increase of statistical significance to the neutral level in the average responses of the members of the sample; consequently, "sending and receiving educational material is not easy".

The researchers think that due to the power shortage and the slow Internet connection in Lebanon, it takes a lot of time to send or receive educational material since it includes videos, pictures, PowerPoint presentations, etc.

5. The item which states "some learners do not have access to proper communication devices (computer, tab, smartphone)" has a relative weight of $75.2 \%$, and the mean is 3.76 , which is greater than the neutral value of 3 . Also, the value of the calculated "T" test is 8.714 , which is greater than the value of tabulated " $T$ " at the significance 0.05 . This means that there is an increase of statistical significance to the neutral level in the average responses of the members of the sample; consequently, "some learners do not have access to proper communication devices (computer, tab, smartphone)".

The researchers believe that due to the current financial and economic crisis in Lebanon, some students do not have a device to log in to their online sessions, and others share the device with a sibling or more (each would log in every other day).

6. The item which states "there are always some absent learners during online sessions" has a relative weight of $84.2 \%$, and the mean is 4.21 , which is greater than the neutral value of 3 . Also, the value of the calculated " $T$ " test is 19.089 , which is greater than the value of 
tabulated " $T$ " at the significance 0.05 . This means that there is an increase of statistical significance to the neutral level in the average responses of the members of the sample; consequently, "there are always some absent learners during online sessions".

The researchers believe that due to the aforementioned problems of electricity shortage, slow Internet connection, and lack of communication devices, there are always some absent learners during online sessions.

7. The item which states "the available online learning evaluation methods (multiple choice, true or false, short answers, etc.) do not accurately measure learners' acquisition of skills and competences" has a relative weight of $87.2 \%$, and the mean is 4.36 , which is greater than the neutral value of 3 . Also, the value of the calculated "T" test is 26.938 , which is greater than the value of tabulated " $T$ " at the significance 0.05 . This means that there is an increase of statistical significance to the neutral level in the average responses of the members of the sample; consequently, "the available online learning evaluation methods (multiple choice, true or false, short answers, etc.) do not accurately measure learners' acquisition of skills and competences".

The researchers think that since the Lebanese curriculum is old, the traditional method of evaluation is still used. Multiple choice, true or false, short answers, etc. need a new approach in updating the eroding Lebanese curriculum. Although many schools are now using concepts and techniques and document analysis approaches, these do not reflect the actual students' evaluation due to the power shortage and/or slow Internet connection since learners might take advantage of the situation and cheat with other learners.

It is clear from the above table that the overall mean of the sample responses for the third domain (Challenges that may hinder online learning) is 4.062 which is greater than the neutral value (3), indicating the sample agreement that there are hindrances to applying online learning at schools. The standard deviation is 0.545 and the relative weight is $81.2 \%$. Also, the value of the calculated T-Test is 24.075 .

The P-value for the hypothesis is equal to 0.000 which is less than the significance level 0.05 ; therefore, the sub-hypothesis that states "there are hindrances to applying online learning at schools" is accepted.

\section{Conclusions}

The study showed that teachers have acquired new skills through online education such as new teaching strategies and active learning techniques that help them deliver sessions in attractive and interesting ways, which disagrees with Lebanon Education Sector (2021) in that teachers at all educational levels are traditional. The study also rendered important findings about the impact of online learning of Economics on acquiring essential skills that comply with the $21^{\text {st }}$-Century skills in light of the COVID-19 pandemic from the Economics teachers' point of view. The results showed that online learners are not acquiring the essential learning skills that comply with the $21^{\text {st }}$-Century skills except for problem-solving skill. They also showed that online learners are not acquiring the essential literacy skills that comply with the $21^{\text {st }}$-Century skills except for the skills of using various forms of communication devices (computers, smartphones, tabs, etc.). In addition, the results showed that online learners are not acquiring the essential life skills that comply with the $21^{\text {st }}$-Century skills except for very few of them. Moreover, the results showed that there are hindrances to applying online learning at schools in Lebanon. These include the low speed of the internet connection which disrupts the online sessions and makes sending or receiving educational material difficult, 
which agrees with Abourjeili \& Harb (2020) and International Telecommunication Union (2015). Another type of hindrance is that the electricity is not reliable. Because of the power failure, there are always some absent learners during online sessions and when electricity is off, so is the internet connection. In addition, some learners do not have access to proper communication devices (computer, tab, smartphone), which agrees with both Hetsevich (2017) and the UNICIF (2021). The final and important hindrance according to the Economics teachers is that the available online learning evaluation methods do not accurately measure learners' acquisition of skills and competences, which agrees with Xiao and Li (2020).

Based on the above results, the researchers have some recommendations. There is no doubt that the Lebanese national curriculum is old and not suitable for online education since it was last updated in the year 2000. To apply an online approach, the eroding curriculum should be modified for online use. Thus, it would currently be better to adopt blended learning without having to totally rely on e-learning taking the health and economic conditions into consideration. Moreover, parallel with blended learning, the CRDP should conduct continuous training sessions and supply electronic resources for teachers to be able to prepare, manage and lead successful and fruitful online sessions. In addition, the Ministry of Education and Higher Education should also supply teachers with guidance and see that their needs are fulfilled so that their only focus would be the learners. Needless to say, if the government did not take actual measures to improve the electric supply and the Internet connection, the online education as a whole would not be efficient. Future suggested research may include assessing the impact of online education on undergraduate students' acquiring essential skills for their life and careers. In addition, further research may be conducted to compare the impact of online education on acquiring skills between students of the public sector and students of the private sector.

\section{References}

Abourjeili, S.A. \& Harb, S. (2020). The Deteriorated Educational Reality in Lebanon: Towards "Another" Critical Approach. Available for download from the Arab Reform Initiative official page: https://www.arab-reform.net/wpcontent/uploads/pdf/Arab_Reform_Initiative_en_the-deteriorated-educational-reality-inlebanon-towards-another-criticalapproach_14565.pdf?ver=382b46f8997159afd3d1aee43a668c83

Alshamrani, M. (2019). An Investigation of the Advantages and Disadvantages of Online Education. A thesis submitted to Auckland University of Technology in partial fulfilment of the requirements for the degree of a Master of Computer and Information Sciences. Available online at: http://hdl.handle.net/10292/12479

Arley-Fonseca, M. \& Brizuela-Gutiérrez, T., (2020). Enhancing the Language Learning Process of Students in the Costa Rican Educational System by Considering the Use of Authentic Materials in the EFL Classroom. Revista Espiga, Vol. 20, no. 40, pp. 121-137. Available online at: https://www.redalyc.org/journal/4678/467863794006/html/ 
Association of College and Research Libraries (ACRL), (2015). Framework for Information Literacy. Available for download at: http://www.ala.org/acrl/files/issues/infolit/framework.pdf

Axmedova T.B, \& Kenjayeva N.D. (2021). Advantages and Disadvantages of Online Learning. Eurasian Journal of Humanities and Social Sciences, 3, 48-50. Retrieved from: https://geniusjournals.org/index.php/ejhss/article/view/240

Barak, M. \& Levenberg, A. (2016). Flexible Thinking in Learning: An Individual Differences Measure for Learning in Technology-enhanced Environments. Computers and Education, Vol. 99, pp: 39-52. Available online at: http://dx.doi.org/10.1016/j.compedu.2016.04.003

Bialik, M. \& Fadel C., (2015). Skills for the $21^{\text {st }}$-Century: What Should Students Learn? Center for Curriculum Redesign (CCR). Available online at: https://curriculumredesign.org/wp-content/uploads/CCR-Skills_FINAL_June2015.pdf

Bossér, U., Lindahl, M., (2019). Students' Positioning in the Classroom: a Study of TeacherStudent Interactions in a Socioscientific Issue Context. Research in Science Education, 49, 371-390. https://doi.org/10.1007/s11165-017-9627-1

Chitra, A.P. and Raj, M. A. (2018). E-learning, Journal of Applied and Advanced Research. Vol. 3, Suppl. 1, pp: S11-S13. Retrieved on Feb. 12 ${ }^{\text {th }}, 2021$ from: http://dx.doi.org/10.21839/jaar.2018.v3iS1.158

Department of Education and Training, Melbourne, (2020). High Impact Teaching Strategies - Excellence in teaching and learning. Available at the official webpage of the State of Victoria: https://www.education.vic.gov.au/Documents/school/teachers/support/highimpact-teaching-strategies.pdf

Dublin, L. (2003). If You Only Look under the Street Lamps...Or Nine e-Learning Myths. The e-Learning Developers' Journal. Retrieved on Feb.22 ${ }^{\text {nd }}, 2021$ from: https://www.learningguild.com/pdf/2/061603man.pdf

Edwards, C., \& Fritz, J. H. (1997). Evaluation of three educational online delivery approaches. (ERIC Document Reproduction Service No. ED 430-516). Available at: https://eric.ed.gov/?id=ED430516

Ferriman. J. (2014). 10 Benefits of Using E-learning. LearnDash. Retrieved on Feb. 13 ${ }^{\text {th }}$, 2021 from: https://www.learndash.com/10-benefits-of-using-elearning/

Firmansyah, R. \& Putri, D.M. \& Wicaksono, M.G. \& Putri, S.F. \& Widianto, A.A. (2021). The Univerity Students' Perspectives on the Advantages and Disadvantages of Online Learning Due to COVID-19. Advances in Economics, Business and Management Research. Vol 183, pp: 120-124.

Florida Center for Instructional Technology (FCIT), (2009). A teacher's guide to distance learning. Available online at: https://fcit.usf.edu/distance/

Fry, K. (2001). E-learning markets and providers: some issues and prospects. Education Training, Vol. 43 No. 4/5, pp. 233-239. https://doi.org/10.1108/EUM0000000005484

Griffin, P. \& Care, E. (2015). Assessment and Teaching of $21^{\text {st }}$-Century Skills-Methods and Approach. Springer, DOI 10.1007/978-94-017-9395-7

Gvaramadze, I. (2012). Developing Generic Competences in Online Virtual Education Programs at the University of Deusto. Campus-Wide Information Systems, Vol. 29, No. 1, pp: 4-20. Available online at https://doi.org/10.1108/10650741211192028 
Halverson, L.R., Graham, C.R., Spring, K.J., \& Drysdale, J.S. (2012). An Analysis of High Impact Scholarship and Publication Trends in Blended Learning. Distance Education, Vol. 33, No. 3, pp: 381-413. Available at: https://doi.org/10.1080/01587919.2012.723166

Hetsevich. I. (2017). Advantages and Disadvantages of E-Learning Technologies for Students. Joomlms. https://www.joomlms.com/blog/guest-posts/elearning-advantagesdisadvantages.html

Holmes, B. \& Gardner, J. (2006). E-Learning: Concepts and Practice, London: SAGE Publications. http://dx.doi.org/10.4135/9781446212585

Indeed Editorial Team (2020). Indeed Career Guide, Social Skills: Definition and Examples. Available online at: https://www.indeed.com/career-advice/careerdevelopment/social-skills

International Telecommunication Union, "The State of Broadband," September 2015. Available online at: https://www.broadbandcommission.org/Documents/reports/bbannualreport2015.pdf

Islam, N., Beer, M., \& Slack, F. (2015). E-learning Challenges Faced by Academics in Higher Education, Journal of Education and Training Studies, Vol. 3, No. 5, pp: 102-112. https://doi.org/10.11114/jets.v3i5.947

Jethro, O.O., Grace, A.M., \& Thomas, A.K. (2012). E-learning and Its Effects on Teaching and Learning in a Global Age. International Journal of Academic Research in business and Social Sciences, Vol. 2, No. 1, pp: 203-210. Available at: https://ijeim.iseeadyar.org/articles/e-learning-and-its-effects-on-teaching-and-learning-ina-global-age

Kivunja, C., (2104) Do You Want Your Students to Be Job-Ready with $21^{\text {st }}$-Century Skills? Change Pedagogies: A Pedagogical Paradigm Shift from Vygotskyian Social Constructivism to Critical Thinking, Problem Solving and Siemens' Digital Connectivism. International Journal of Higher Education, Vol. 3, No. 3, pp: 81-91. Available online at: https://eric.ed.gov/?id=EJ1067554

Koumi, J (2006). Designing Educational Video and Multimedia for Open and Flexible (Distance) Learning. Routledge, England. https://doi.org/10.4324/9780203966280

Lai, E.R. (2011). Collaboration: A Literature Review. Pearson Publications.

Lebanon Education Sector (October 2021). Lebanon: Education at a Tipping Point (Education Sector Advocacy Brief). Available at: https://www.nrc.no/globalassets/pdf/reports/education-at-a-tipping-point/education-at-atipping-point--lebanon-october-2021.pdf

Mouchantaf, M. (2020). The COVID-19 pandemic: Challenges Faced and Lessons Learned regarding Distance Learning in Lebanese Higher Education Institutions. Theory and Practice in Language Studies, Vol. 10, No. 10, pp: 1259-1266. DOI: $\underline{10.17507 / \mathrm{tpls.1010.11}}$ 
Oblinger, D. G., \& Hawkins, B. L. (2005). The Myth about E-learning. Educause review. Available at: https://er.educause.edu/articles/2005/1/the-myth-about-elearning. Accessed Jan. $12^{\text {th }}, 2021$.

Organization for Economic Cooperation and Development (OECD, 2005). E-learning in tertiary education. Available at: http://www.oecd.org/education/ceri/35991871.pdf

Organization for Economic Cooperation and Development (OECD, 2020a). Coronavirus: The World Economy at risk. Available at: https://www.oecd.org/berlin/publikationen/InterimEconomic-Assessment-2-March-2020.pdf

Organization for Economic Cooperation and Development (OECD, 2020b). The Impact of Covid-19 on Education: Insights from Education at a Glance 2020. Available at: https://www.oecd.org/education/the-impact-of-covid-19-on-education-insights-educationat-a-glance-2020.pdf

Organization for Economic Cooperation and Development (OECD, 2020c). Learning compass 2030. Available at: https://www.oecd.org/education/2030-project/teaching-andlearning/learning/learning-compass2030/OECD_Learning_Compass_2030_concept_note.pdf

Potter, W. J. (2004). Theory of media literacy: A cognitive approach. Thousand Oaks, Calif: SAGE Publications. http://dx.doi.org/10.4135/9781483328881

Ravaglia, R., Suppes, P, Stillinger, C, Alper, T.M. (1995). Computer-Based Mathematics and Physics for Gifted Students. Gifted Child Quarterly, Vol. 39, Iss. 1, pp: 7-13. https://doi.org/10.1177\%2F001698629503900102

Richard Howe, retrieved online at: https://blogs.brighton.ac.uk/rh593/creativity-in-the-21stcentury-classroom/

Rossi, P.G. (2009). Learning Environment with Artificial Intelligence Elements. Journal of Elearning and Knowledge Society, Vol. 5, no. 1, pp: 67-75. https://doi.org/10.20368/1971$\underline{8829 / 306}$

Rost, J. (1991). Leadership for the twenty-first century. Westport Connecticut: Praeger.

Save the Children International, March, 2021. Lebanon Education Crisis: Raising the Alarm. Available for download at the "Save the Children International" web page: https://reliefweb.int/sites/reliefweb.int/files/resources/Lebanon\%20Education\%20crisis\% 20spotlight.pdf

School Education Gateway, Europe's online platform for school education (June $8^{\text {th }}, 2020$ ). Survey on Online and Distance Learning - Results. Available at the website of the European

Union: https://www.schooleducationgateway.eu/en/pub/viewpoints/surveys/survey-on-onlineteaching.htm

Sherry, L., (1995) Issues in Distance Learning, International Journal of Educational Telecommunications, Vol. 1, No. 4, pp: 337-365. Retrieved on Feb. 15 ${ }^{\text {th }}$, 2021 from: https://www.semanticscholar.org/paper/Issues-in-Distance-Learning$\underline{\text { Sherry/914c13953b88950ac709ba84c4750adece7ba778 }}$

Siegle, D. (2004). The Merging of Literacy and Technology in the $21^{\text {st }}$-Century: A Bonus for Gifted Education. Technology, Vol. 27, No. 2, pp: 32-35. Retrieved May 8, 2021, from: https://files.eric.ed.gov/fulltext/EJ682660.pdf 
The Foundation for Critical Thinking: https://www.criticalthinking.org/pages/definingcritical-thinking/766

UNESCO, (2002). Open and Distance Learning: Trends, Policy and Strategy Considerations. Retrieved on Feb. 14 ${ }^{\text {th }}, 2021$ from: https://unesdoc.unesco.org/ark:/48223/pf0000128463

UNESCO, (2020). Distance Learning Strategies in Response to COVID-19 School Closures. Available at: https://unesdoc.unesco.org/ark:/48223/pf0000373305

UNICEF (June 2021) Lebanon: Children's Future on the Line. Available at: https://reliefweb.int/sites/reliefweb.int/files/resources/Lebanon_childrens_future on the line EN.pdf.pdf

United States Distance Education Association (USDLA), (July 2019). Definition of Distance Learning, Available online at: https://usdla.org/?s=Definition+of+Distance+Learning

World Health Organization (WHO, Jan. 2021). Listings of WHO's Response to Covid-19. Available at: https://www.who.int/news/item/29-06-2020-covidtimeline

Wyse, D. \& Manyukhina, Y. (2018). The Place of Knowledge in Curricula: A Researchinformed Analysis. UCL Institute of Education. Also available online: https://ncca.ie/media/3502/seminar_two_wyse_paper.pdf

Yanarates, E., (2020). A Conceptual Analysis on Media Literacy. Social Scientific Centered Issues, 2(2), 89-102. Available at: https://dergipark.org.tr/en/pub/ssci/issue/57035/846190

Yuhanna, I., Alexandar, A. \& Kachik, A. (2020). Advantages and disadvantages of Online Learning. Journal Educational Verkenning, 1(2), 13-19. https://doi.org/10.48173/jev.v1i2.54

Yulia, H. (2020). Online Learning to Prevent the Spread of Pandemic Corona Virus in Indonesia. ETERNAL. English Teaching Journal, Vol. 11, No. 1. Available online at: https://doi.org/10.26877/eternal.v11i1.6068

\section{Copyrights}

Copyright for this article is retained by the author(s), with first publication rights granted to the journal.

This is an open-access article distributed under the terms and conditions of the Creative Commons Attribution license (http://creativecommons.org/licenses/by/4.0/) 